\title{
Políticas sociais na pós-graduação stricto sensu de Psicologia
}

Ana Ludmila Freire Costa. Universidade Federal do Rio Grande do Norte. Oswaldo Hajime Yamamoto. Universidade Federal do Rio Grande do Norte.

\begin{abstract}
Resumo
Objetiva-se discutir as contribuições da pós-graduação stricto sensu de Psicologia para o debate sobre política social. Analisou-se 105 teses acadêmicas de um total de 824 defendidas no triênio 2007/2009. Atesta-se que a presença do tema ocorre de forma predominantemente pulverizada, ainda que seja objeto prioritário para um conjunto restrito de pesquisadores; há fragilidade teórica nos trabalhos, que assumem caráter essencialmente técnico; e as investigações têm como finalidade melhorias nas políticas sociais, sem questionamento ao ciclo que as demandam. Discute-se a urgência da articulação entre os pesquisadores em torno do tema, da necessidade de aprofundamento do debate teórico e da transformação dos saberes em prática política organizada para que a ciência psicológica possa contribuir efetivamente para o desenvolvimento da sociedade.
\end{abstract}

Palavras-chave: política social; produção científica; função social da Psicologia.

\begin{abstract}
Social policies in Psychology postgraduate courses. It aims to discuss the contributions of Psychology postgraduate studies to understand "social policy". 105 academic theses were analyzed among 824 defended in 2007/2009 triennium. Results point to the existence of the issue in a sprayed way, predominantly, albeit appears as a priority object for a limited set of researchers; majority of these can be characterized by fragility of the theoretical frameworks, in a strictly technical perspective; and the studies aim to improve specific social policies, without questioning why they need to be carried out. Psychological science can only contribute effectively to the society development if academic community promotes a structured articulation around the theme, deepens the theoretical debate and transforms the knowledge built into organized political practice.
\end{abstract}

Keywords: social policy; scientific production; social role of Psychology.

\section{Resumen}

Las políticas sociales en los cursos de postgrado de Psicología. El artículo objetiva analizar las contribuciones de los estudios de postgrado en Psicología para el debate acerca del tema "política social". Fueron analizadas 105 tesis académicas de las 824 defendidas entre 2007/2009. Los resultados apuntan que el tema existe predominantemente en una manera dispersa, aunque aparezca como un objeto de prioridad para un conjunto limitado de investigadores; mayoría de los estudios son caracterizados por la fragilidad de los marcos teóricos y por adoptar un punto de vista estrictamente técnico; y las investigaciones tienen como objetivo mejorar las políticas sociales específicas, sin cuestionar por qué tienen que llevarse a cabo. La conclusión es que la ciencia psicológica sólo puede contribuir eficazmente al desarrollo de la sociedad, si la comunidad académica promueve una articulación estructurada en torno al tema, se profundiza el debate teórico y transforma el conocimiento incorporado en la práctica política organizada.

Palabras clave: política social; producción científica; papel social de la Psicología. 
A análise do desenvolvimento da política científica nacional aponta, como sua principal marca, para a expansão contínua do sistema de pós-graduação stricto sensu. Pelos índices que apresenta (em relação à quantidade de cursos existentes, docentes envolvidos e bolsas de estudo, por exemplo), tal modalidade é considerada a experiência brasileira mais exitosa do sistema educacional, referência em toda América Latina, a despeito da recenticidade de sua regulamentação e estruturação. Muitos são os aspectos que contribuíram para o sucesso desse empreendimento, com destaque para o planejamento orquestrado por um metódico sistema de avaliação institucional, do investimento contínuo por parte do poder público e da mobilização permanente da comunidade científico-acadêmica nacional.

Diante de investimentos públicos crescentes na ciência brasileira, não é impertinente questionar para qual direção ela tem apontado. Como sumariza Dantas (2004, p. 164), "até que ponto o produto intelectual da pós-graduação no Brasil está contribuindo para a redução das desigualdades sociais, melhoria da qualidade de vida da população e para o desenvolvimento socioeconômico do país?"

Para efeitos de análise, toma-se o caso da Psicologia como exemplo: entre as Ciências Humanas, a área ocupa o segundo lugar em quantidade de programas de pós-graduação no Brasil, tendo participado um total de 120 cursos (sendo 73 de mestrado acadêmico e 47 de doutorado) da avaliação da CAPES (Coordenação de Aperfeiçoamento de Pessoal de Nível Superior) em 2013. Este número equivale a um crescimento de quase $300 \%$ considerando como parâmetro a quantidade existente no triênio 1998-2000, período que inaugurou a nova sistemática de avaliação para credenciamento dos programas que se mantém ainda hoje (CAPES, 2013).

No que se refere à articulação entre a pós-graduação stricto sensu de Psicologia e desenvolvimento social, uma das alternativas possíveis é através da ampliação da compreensão acerca das políticas sociais ${ }^{1}$.

Considerada, cada vez mais, uma área do campo do bem-estar social, a Psicologia tem passado por uma transição em relação ao seu perfil profissional: de um trabalho essencialmente autônomo, de consultório privado e caráter clínico-curativo, o contingente de psicólogos em emprego assalariado, principalmente em serviços públicos, tem aumentado progressivamente. Ainda que os dados sobre isso não sejam consensuais, o último grande estudo nacional sobre a profissão indica o campo das políticas sociais como contexto laboral para mais de $40 \%$ dos psicólogos que participaram da pesquisa (Bastos \& Gondim, 2010).

Contudo, análises sobre o trabalho aí desenvolvido têm apontado críticas e diversos estudos chamam a atenção para uma atuação limitada e desqualificada, distante das demandas da população atendida (a exemplo de Aragaki, Spink, \& Bernardes, 2012; Guzzo, Marçal, \& Rybka, 2014; Oliveira, Dantas, Solon, \& Amorim, 2011). Assim, o debate atual intenta concretizar a expectativa de que o psicólogo consiga ampliar o alcance de sua ação profissional em direção a reais transformações nas condições de vida daqueles que necessitam. Para tanto, é preciso que a profissão compreenda de uma maneira mais qualificada as determinações macroestruturais que condicionam este campo.

É nesse sentido que se questiona de que forma as políticas sociais figuram como um campo de interesse e preocupação para os pesquisadores de Psicologia. Com isso, não se está sendo ingênuo em supor que a pesquisa científica tenha responsabilidade pelo equacionamento de problemas socioeconômicos estruturais. De outro modo, o que está em questão é o compromisso da pesquisa científica em contribuir para o desenvolvimento da sociedade, papel fundamental por ser, ao mesmo tempo, norteadora e reveladora das práticas que subsidia. É a partir deste debate que se propõe como objetivo discutir as possibilidades de contribuição da ciência psicológica para o debate sobre política social.

\section{Método}

A estratégia de investigação adotada teve como base a análise da produção científica de Psicologia sobre políticas sociais oriunda dos programas de pós-graduação stricto sensu.

\section{Objeto}

Foram aplicados três recortes para definição da produção científica a ser analisada: (1) tipo de publicação (optou-se pelas teses acadêmicas, considerando critérios como acesso, nível de detalhamento das informações e importância para o desenvolvimento dos cursos e pesquisadores); (2) período de publicação (teses defendidas entre 2007-2009, que apresentava o material mais atual disponível no momento da coleta) e (3) tema abordado (foram elaborados cinco critérios temáticos a partir da literatura especializada: Políticas Públicas/Sociais e 
Cidadania; Políticas Setoriais e Legislação; Programas, Serviços, Unidades e Instituições Públicos; Vulnerabilidades e Risco Social, e Movimentos e Controle Social).

\section{Instrumentos}

Foram utilizados três tipos de instrumentos: (1) Cadernos de Indicadores, disponíveis na página eletrônica da CAPES para os cursos de doutorado de Psicologia ativos no momento da coleta, dos quais foram obtidas informações sobre os cursos e os títulos e autores das teses disponíveis no período estudado; (2) Currículos dos autores e orientadores das teses obtidos a partir da Plataforma Lattes; (3) Teses propriamente ditas, as quais foram lidas na íntegra a fim de se coletar dados sobre o conteúdo dos trabalhos desenvolvidos.

\section{Procedimento de Coleta de Dados}

A coleta dos dados foi realizada em duas etapas: seleção, busca e organização das teses acadêmicas; e coleta dos dados nas teses e nos demais instrumentos.

A primeira etapa consistiu em três subetapas: (1) Busca dos resumos nos Banco de Teses da CAPES e no Banco Digital de Teses e Dissertações do Instituto Brasileiro de Informação em Ciência e Tecnologia (BDTD/IBICT), ambos disponíveis online, a partir da listagem de teses obtidas nos Cadernos de Indicadores, o que indicou 824 teses defendidas no período. A leitura destes resumos serviu para aplicação do recorte temático, o que retornou o número de 105 teses sobre políticas sociais; (2) Análise de juízes (três pesquisadores mestres, com experiência de pesquisa sobre a temática) a partir de aproximadamente $10 \%$ do total de resumos (83 resumos). O resultado do procedimento apontou um índice de concordância de $91,5 \%$ entre os três avaliadores; e (3) Busca das teses em formato integral por meio da busca direta nos portais eletrônicos Domínio Público, BDTD/IBICT, Google Acadêmico e bancos de teses digitais das instituições que sediam os programas; contato com os alunos-autores e orientadores por endereço eletrônico; e solicitação às bibliotecas das IES que sediam os programas onde foram produzidas e defendidas. Com isso, retornou-se um montante de 99 teses, utilizadas para as análises do conteúdo. Para as análises cientométricas (caraterização dos programas e atores), foram utilizadas as 105 teses originalmente selecionadas para compor a amostra.

A segunda etapa, a coleta dos dados propriamente dita, também foi realizada a partir de três subetapas: (1)
Definição das variáveis a serem analisadas na amostra selecionada. Para tanto, procedeu-se ao levantamento de material bibliográfico com dados de análise de produção científica na Psicologia brasileira. A leitura destes textos possibilitou a montagem de um quadro com variáveis referidas pelos autores e acréscimo de outras, considerando a pertinência para o escopo deste estudo. (2) Estudo piloto a fim de testar as variáveis eleitas. (3) Coleta dos dados a partir da leitura integral do material e preenchimento do banco de dados, organizado em três planilhas eletrônicas, conforme a natureza do dado a ser coletado (como apresenta a Tabela 1):

\section{Procedimento de Análise dos dados}

Uma vez que os dados foram coletados e registrados em planilhas eletrônicas, procedeu-se a sua sistematização e análise por meio de dois processos: categorização e análises de estatística descritiva.

\section{Resultados e discussão}

Os principais resultados obtidos foram sistematizados em torno de três eixos de análise: a dimensão ocupada pelo tema no conjunto de programas de Psicologia, características da produção científica sobre políticas sociais e finalidades postas por essa produção.

\section{A dimensão do Tema "Políticas Sociais" na Pós-Graduação Stricto Sensu de Psicologia}

As 105 teses acadêmicas de Psicologia sobre políticas sociais foram produzidas em 20 distintos cursos de doutorado (dos 29 ativos no período estudado) e orientadas por 73 docentes do sistema de pós-graduação.

A análise deste quadro, que revela o índice de $12,7 \%$ das 824 defendidas no interregno 2007-2009, precisa considerar, pelo menos, duas perspectivas. Primeiro, como um cenário positivo, por atestar a presença do tema na produção científica da área. Este percentual se torna ainda mais importante quando se compara com a diversidade de temas que compõem o escopo da pesquisa científica de Psicologia e a recenticidade da aproximação entre Psicologia e políticas sociais. A segunda perspectiva de análise aponta para o fato de que aproximadamente $90 \%$ de toda a produção científica de Psicologia mantêm-se alheia a esta temática. Visando reunir outros elementos para aprofundar o debate, procedeu-se a uma caracterização mais detalhada da presença desta produção. 
Políticas sociais, pós-graduação, Psicologia

Tabela 1. Variáveis Coletadas e Fontes de Informação a Partir dos Bancos de Dados Criados.

\begin{tabular}{lcc}
\hline Banco de dados & Fonte de informação & Variáveis \\
\hline Banco 1: Programas & Cadernos de Indicadores & $\begin{array}{c}\text { Unidade da Federação } \\
\text { Nome das Áreas de Concentração } \\
\text { Quantidade de teses defendidas no triênio }\end{array}$ \\
Banco 2: Orientadores & Currículos da Plataforma Lattes & $\begin{array}{c}\text { Quantidade de docentes que orientaram teses no triênio } \\
\text { Quantidade de teses orientadas no triênio }\end{array}$ \\
Banco 3: Conteúdo & Nome das Linhas de pesquisa do orientador & Tema \\
& Leitura integral das teses & Concepção de política social \\
Abordagem teórica \\
Objetivos da tese
\end{tabular}

Alguns dados indicam que, apesar de presente, não se trata de tema consolidado e sistematizado na Psicologia científica. De outro modo, percebe-se uma pulverização marcante das pesquisas sobre políticas sociais conduzidas pela área, o que pode ser compreendido a partir de dois conjuntos de aspectos: a dimensão que o tema ocupa na produção do programa e na produção dos docentes-orientadores. Para iniciar esta análise, observe-se a Tabela 2:

Tabela 2. Distribuição dos Cursos de Doutorado de Psicologia em Relação à Proporção entre a Quantidade de Teses Produzidas pelo Curso no Triênio 2007/2009 e a Quantidade de Teses sobre Política Social no Mesmo Período.

\begin{tabular}{cc}
\hline Proporção de teses (PS/Triênio) & Quantidade de cursos de doutorado \\
\hline Acima de $30 \%$ & 2 cursos \\
Entre $20 \%$ e $30 \%$ & 5 cursos \\
Entre $10 \%$ e $20 \%$ & 6 cursos \\
Até $10 \%$ & 7 cursos \\
0 & 9 cursos \\
\hline
\end{tabular}

A análise da Tabela 2 indica o agrupamento dos dados em três conjuntos. No primeiro grupo se encontram dois cursos de doutorado que no período 2007/2009 tiveram mais de $30 \%$ de teses defendidas relativas ao tema das políticas sociais, índice que aponta a importância do tema para o programa. Nestes dois casos, esta produção se distribuiu entre vários docentes (de seis a dez), sendo que alguns deles concentraram parte dessas teses. O segundo bloco reúne 11 cursos cujas teses sobre políticas sociais ocupam um percentual médio aproximado de $20 \%$ em relação àquelas defendidas no triênio em tela, o que pode significar que o tema, apesar de não estar em lugar central, também não pode ser tomado como mero resíduo. Vale a pena mencionar que, nestes casos, a produção não se repetiu entre os docentes, havendo tantos orientadores quanto o número de teses em cada programa, o que pode indicar uma produção residual para cada orientador tomado individualmente. Em relação ao terceiro bloco, composto por 13 cursos, refere-se aos casos em que a quantidade de teses sobre políticas sociais é quase inexpressiva frente ao total de teses defendido no triênio, não chegando a 10\%. Aqui, percebe-se que nos cursos em que houve mais de quatro teses sobre o tema, estas produções estão relacionadas a pesquisadores específicos, em vez de se referir a uma tese por docente distinto. Nestes casos, entende-se que o tema das políticas sociais é tributário de certos pesquisadores e não, do programa, como sugere o primeiro bloco.

Ainda no tocante à distribuição da produção científica de Psicologia sobre políticas sociais no conjunto dos programas, dois dados merecem atenção.

Geograficamente, o tema está presente de forma diluída entre as Unidades da Federação (UF): das 11 UFs com cursos de doutorado ativos no momento da coleta dos dados, em nove havia programas com teses sobre políticas sociais no período estudado.

No que se refere às Áreas de Concentração, apenas dois cursos de doutorado trazem esta temática explicitamente descrita em pelo menos uma de suas Áreas, o que indica a não centralidade do tema para a grande maioria dos cursos aqui estudados. Por outro lado, chama a atenção o fato de existir dois cursos que conferem tamanha importância às políticas sociais, desde sua concepção.

O segundo conjunto de dados que revelam a pulverização do tema das políticas sociais nas pesquisas conduzidas pela área diz respeito à atuação dos docentes-orientadores. 
Identificou-se que 43 docentes que orientaram alguma tese sobre políticas sociais no período estudado não trazem este tema em sua(s) linha(s) de pesquisa (o que equivale a aproximadamente $60 \%$ dos orientadores da amostra analisada). Quando somados àqueles que dedicam parcela reduzida de suas linhas de pesquisa a esta temática (ou seja, as linhas de pesquisa sobre política social correspondem ao intervalo de 10 a $30 \%$ do total de linhas de pesquisa desenvolvidas pelo docente), o índice chega a 70\%. De outro modo, apenas uma parcela reduzida (em torno de 15\%) de todos os orientadores analisados se dedicam exclusivamente ao estudo das políticas sociais (em que $100 \%$ de suas linhas são sobre esta temática). Ou seja, mesmo dentre os docentes que orientaram alguma tese sobre políticas sociais no período estudado, o tema é periférico em relação as suas áreas de estudo.

Estes números, em conjunto, revelam o caráter residual do tema das políticas sociais na pós-graduação de Psicologia: para uma parte significativa dos docentes e dos cursos, "política social" ocupa mais um papel coadjuvante do que protagonista. Este cenário pode consistir uma dificuldade na configuração das políticas sociais como campo de conhecimento da Psicologia, limitando a acumulação do conhecimento produzido a respeito deste tema, que termina por consistir em trabalhos pontuais e não, em programa de estudos sistematizado.

Tentar entender este quadro requer uma análise articulada ao contexto científico como um todo. Como afirma Mészáros (2004), os ramos da ciência e da tecnologia têm sido progressivamente redefinidos em função do atendimento aos objetivos das estruturas econômicas e político-organizacionais que sustentam o modo de produção capitalista e a produção intelectual, em nível global, tem se voltado para auxiliar sua reprodução e crescimento.

Em uma análise comparativa dos temas estudados pela Psicologia científica brasileira, percebe-se a força das áreas que ressaltam os aspectos individuais do comportamento humano, o que pode auxiliar o processo de "psicologização" e naturalização dos fenômenos sociais. A título de ilustração, das 229 linhas de pesquisa dos 73 programas de Psicologia ativos em 2012, mais de $25 \%$ referiam-se a Psicologia Clínica, Processos Psicológicos Básicos e Análise Experimental do Comportamento (CAPES, 2013). Neste mesmo levantamento, a Psicologia Comunitária foi considerada sub-representada pelos autores por estar presente em menos de $2 \%$ das linhas. Em outro mapeamento, desta vez temático e não por áreas da Psicologia, Féres-Carneiro, Bastos, Feitosa,
Seidl-de-Moura e Yamamoto (2010) encontraram que o tema "Subjetividade" estava presente em 19\% das linhas dos programas, "Psicoterapia" em 12,8\% e "Psicanálise" em 10,2\%; "Processos Cognitivos" e "Bases biológicas do Comportamento" em 9,7\% e 7,5\%, respectivamente; enquanto que "Políticas Públicas" em apenas 6,2\%.

Com isso, não se está querendo afirmar que a produção científica voltada para os fenômenos sociais (e tentativas de equacionamento dos problemas daí decorrentes) não ocorra ou encontre dificuldade de ser publicada e acessada - as teses aqui analisadas contradiriam esta suposição. O que se está pontuando é a não centralidade deste objeto de estudo para a comunidade acadêmica da área, fazendo com que o tema das políticas sociais ocorra, principalmente, de forma pontual, não parecendo seguir a direção da construção de um arcabouço teórico sólido e robusto.

Cabe ressaltar que as análises sobre a dimensão ocupada pelo tema nos programas de pós-graduação stricto sensu da área dizem apenas do contexto e das condições em que a produção científica ocorre, pouco informando sobre o real potencial desta para contribuir na construção de respostas aos problemas sociais postos pela ordem social. Assim, entende-se que o fortalecimento do campo de estudos trata-se de um primeiro passo, imprescindível, para a construção de uma crítica transformadora, mas, em absoluto, pode ser suficiente para que isso ocorra.

\section{Características das Teses Acadêmicas de Psicologia sobre Políticas Sociais}

Da análise das teses de Psicologia sobre políticas sociais, uma característica referente à estrutura interna das pesquisas se destaca: trata-se do fato de que grande parte das teses está articulada diretamente a uma determinada realidade prática, fortemente embasada em dados empíricos, mas negligenciando, por vezes, o debate ontológico-epistemológico mais amplo que explica esta realidade.

Os resultados obtidos refletem essa situação a partir de três conjuntos de variáveis: os temas de análise, os objetivos propostos e as abordagens teórico-conceituais adotadas.

Em relação à distribuição dos temas estudados, tomando como referência os critérios utilizados para aplicação do recorte temático, $70 \%$ das teses analisadas referem-se ao estudo de alguma política específica, principalmente os instrumentos de sua operacionalização (critérios: "Políticas Setoriais e Legislação" e "Programas, 
Serviços, Unidades e Instituições Públicos"). Exemplos disso são as pesquisas que tratam de um serviço específico (como o ambulatório de atendimento a gestantes diabéticas em um hospital público), um projeto (como "Arteterapia no contexto de violência doméstica"), um programa (como o "Diversidade na Universidade", em atendimento à chamada Lei de Cotas), entre outros.

Fazendo uma análise dos setores aos quais se referem estes programas, serviços ou legislação, percebe-se que há uma articulação direta entre os campos de inserção profissional e os temas da produção científica: $70 \%$ das teses classificadas sob estes temas referem-se às políticas que mais absorvem psicólogos, a saber, os campos da saúde, justiça, segurança pública e assistência social. Isto leva à ideia de que parte considerável desta produção científica (o que corresponde a quase $50 \%$ de todas as teses analisadas neste trabalho) está diretamente atrelada à própria prática psicológica, em comparação com análises sobre outras políticas que não absorvem (ou absorvem pouco) os profissionais da área, revelando o quanto a ciência psicológica direciona sua contribuição para a própria atuação profissional, e não para demandas do contexto, restringindo sua relevância social. As rupturas com este cenário são percebidas pela ocorrência de teses sobre temas como Políticas de Emprego e Renda, Desenvolvimento Urbano e Questão Agrária, políticas que não contam, costumeiramente, com psicólogos em seus quadros.

Ainda no que se refere à classificação temática, viu-se que oito de 12 teses que se dedicam ao estudo de fenômenos relacionados à "questão social" (critério "Vulnerabilidades e Risco Social"), o fazem por meio da análise de suas refrações práticas no cotidiano da população (saúde, violência, desemprego etc.), pouco se dedicando a análises do contexto macroestrutural que as condicionam. Também, há de se ressaltar que das 13 teses voltadas ao estudo de movimentos sociais e demais organizações da sociedade (critério "Movimentos e Controle Social"), apenas em uma há o debate teórico a respeito do papel da sociedade civil no contexto sócio-histórico, sendo que nas demais a discussão se limita à caracterização ou intervenção neste campo. A ausência de teses de Psicologia sobre os conselhos de direitos e debates em torno de concepções de cidadania, emancipação e/ou protagonismo social dão algumas pistas do quanto a área ainda precisa avançar em sua sistematização teórica a respeito do tema "política social".

A segunda variável cuja análise embasa esta discussão diz respeito aos objetivos propostos pelas teses analisadas. Eles foram categorizados a partir do eixo principal dos estudos e se distribuem em três categorias.

O objetivo mais frequente foi a caracterização de atores, que reúne 42 teses, das quais 32 têm como foco os beneficiários ou a população-alvo de intervenções de corte social. Nesses casos, a produção científica da Psicologia reconhece na população pobre um estrato diferenciado de público que necessita ser conhecido e estudado, de modo a ser conferido um "tratamento" específico. No que se refere ao estudo dos profissionais atuantes em políticas sociais, presente em 12 teses, isto pode representar um avanço no reconhecimento de um dentre vários elementos que condicionam o trabalho em políticas sociais. Tanto Macedo e Dimenstein (2012), quanto Oliveira e Amorim (2012) e Yamamoto (2012) ressaltam dificuldades relacionadas ao exercício profissional neste contexto que estão além do escopo da Psicologia, e uma delas seria a forma como os profissionais concebem os pressupostos e participam das ações.

O segundo objetivo mais frequente nas teses analisadas foi a descrição e/ou avaliação de um determinado serviço, programa ou instituição, presente em um conjunto de 38 teses. Destas, pouco mais de $2 / 3$ tomam como unidade de análise instituições ou práticas relativos a campos pioneiros de inserção do psicólogo no que se refere às políticas sociais, nomeadamente na saúde (como instituições de saúde mental e de atenção básica em saúde), na justiça e segurança pública (como instituições de acolhimento, varas judiciais e instituições policial e prisional) e voltadas à Psicologia Social Comunitária (pela via dos projetos sociais, movimentos sociais e instituições do "terceiro setor").

Por fim, 20\% da amostra declarou como objetivo a análise da atuação do psicólogo nas políticas sociais. Foram analisadas atividades desenvolvidas, instrumentos utilizados, pressupostos teóricos que subsidiam as ações, discursos e sentidos produzidos no cotidiano de trabalho, dentre outros aspectos relativos à prática profissional do psicólogo.

Estas duas variáveis de análise (distribuição temática e objetivos propostos) ajudam a mostrar o quanto a produção analisada se sustenta sobre uma base quase exclusivamente empírica, respondendo diretamente a questões concretas do cotidiano.

Outros elementos apontam para dificuldades no plano teórico que cercam estes estudos, o que consistiria em limites para a consolidação deste campo na Psicologia. Eles se referem aos dados acerca dos fundamentos teóricos dos trabalhos. 
O índice de que apenas 15\% dos estudos analisados trazem uma concepção teórica de política social chama a atenção. Do total de 99 teses, foram 19 aquelas que buscaram situar as políticas sociais em um marco conceitual, indicando o reconhecimento da importância do delineamento deste fenômeno. A despeito das distinções entre as diferentes concepções utilizadas (Marxismo, Teoria da cidadania, Perspectiva do Serviço Social, Funcionalismo, Pluralismo e Teorias econômicas ${ }^{2}$ ), o que estas teses guardam em comum é o debate sobre a necessidade de intervenção sobre a realidade para lidar com os efeitos das forças sociais tais como se dão hoje, divergindo quanto aos motivos e aos objetivos esperados com isso.

Somando esse dado à discussão sobre recortes temáticos e objetivos propostos, percebe-se certa fragilidade ou negligência na definição dos marcos ontológico-epistemológicos, ao passo em que a produção científica se refugia no nível essencialmente técnico. Reflete-se, assim, sobre a possibilidade de que esteja havendo uma tendência à transformação da construção do conhecimento em uma perspectiva majoritariamente pragmática. Para Löwy (2007), nesta condição, os pesquisadores atuam mais como técnicos do que cientistas, uma vez que tomam a realidade como dada, sem questionamentos aos determinantes que a produzem e consideram as práticas atuais de intervenção nesta realidade, neste caso, as políticas sociais, como única alternativa possível. Esse modo de fazer ciência, então, encontra-se limitado quanto à possibilidade de revelar caminhos realmente transformadores das condições de vida da população.

Em relação às abordagens teórico-metodológicas (referenciais teóricos ou principais autores que subsidiaram a análise dos dados empreendida pelos pesquisadores), a produção científica da Psicologia sobre políticas sociais está assentada em um campo teórico diverso e complexo que, para efeitos de análise, foram agrupados em quatro blocos.

O primeiro reúne 15 teses que não explicitam a abordagem teórica utilizada para definições da pesquisa e análise dos dados, o que pode ser interpretado como tendo sido produzidas com base exclusiva no material empírico. Sobre isso, González-Rey (2013) afirma que não são raros na Psicologia trabalhos que desconsideram a íntima relação que deve haver entre o teórico, o epistemológico e o metodológico. Para o autor, tal situação colocaria em risco o exercício criativo do pesquisador, impossibilitando produções científicas mais abrangentes, robustas, complexas e inovadoras, que trazem contribuições efetivas para o corpo de conhecimento da disciplina.

O segundo grupo $(n=15)$ refere-se às perspectivas centradas no conceito de trabalho/atividade (Ergologia, Psicodinâmica do Trabalho e Clínica da Atividade) e de Desenvolvimento Humano, que não guardam relação direta com o estudo de fenômenos sociais, tampouco são abordagens preponderantes na Psicologia. Trata-se de um montante residual, que pode indicar tanto a permeabilidade do tema das políticas sociais a ângulos de análise diversos, quanto o alcance amplo de certas teorias, que podem ser extrapoladas para além de um fenômeno específico.

No terceiro, estão presentes o que foi chamado por Lacerda Junior (2013) de "santíssima trindade", ou seja, as abordagens consideradas clássicas da Psicologia e priorizadas nos cursos de graduação: a Psicanálise, a Fenomenologia e as Abordagens Cognitivo-Comportamentais. Apesar de aqui não figurarem hegemonicamente nos estudos sobre políticas sociais, comparecem em $20 \%$ da amostra analisada, o que pode indicar um viés clínico, individualizante e psicologizante de fenômenos sociais na Psicologia.

A referência a uma tendência à fragilidade teórica como característica da produção científica de Psicologia sobre política social, entretanto, não significa a total ausência de trabalhos que se preocupam com a necessária fundamentação para enquadramento dos dados empíricos, condição essencial para a construção de uma crítica efetiva. Isto pode ser depreendido pela análise do quarto bloco, que reúne metade das teses.

Nele foram agrupadas as abordagens que têm em comum a consideração de uma dimensão social na concepção de sujeito, sejam elas teorias próprias da Psicologia ou não, ainda que guardem diferenças expressivas entre si: as teorias sociológicas/críticas e as teorias pós-modernas ${ }^{3}$. Este conjunto reúne aproximadamente $50 \%$ da produção científica analisada, o que aponta para uma parcela de pesquisadores que reconhece a necessidade de recorrer a teorias de cariz social para o estudo das políticas sociais, considerando distintas vias de relação entre contexto social e construção da realidade e do sujeito.

Importante ressaltar que não se está tomando aqui robustez teórica/científica como sinônimo de validade ética/social: Löwy (2007) explica que o fato de um estudo ter coerência lógica e vigor teórico, atendendo aos critérios de qualidade da pesquisa científica, não significa, por dedução, tratar-se de um trabalho que se volta para o 
desenvolvimento da sociedade, que tenha como norte as demandas que afligem o conjunto da população. Entende-se, portanto, que a argumentação teórica da pesquisa científica não está necessariamente relacionada com o seu direcionamento e a ideia de que o desenvolvimento científico naturalmente leva à resolução dos problemas sociais, já se mostrou consistir em falácia.

Portanto, para avaliar a possibilidade de tendências críticas e progressistas na produção científica de Psicologia, recorreu-se à análise do direcionamento buscado pelas pesquisas analisadas.

\section{Finalidade da Produção Científica de Psicologia sobre Políticas Sociais}

Com o intuito de debater a finalidade da produção científica em tela, duas variáveis foram analisadas: as justificativas para realização das teses e o âmbito de contribuição esperada dos trabalhos.

No que se refere às justificativas, buscou-se identificar, nas teses, a qual aspecto os autores atribuem a importância do seu trabalho. A justificativa mais recorrente (37 teses) diz respeito aos estudos que, em geral, destacam a importância de avaliar o impacto de determinado programa, acompanhar a evolução de uma determinada política ou verificar como ocorre a operacionalização de algum direito social. Este reconhecimento de que a Psicologia tem potencial para auxiliar gestores públicos e elaboradores de políticas ainda é incipiente no Brasil, havendo carência de estudos que auxiliem a dimensionar a participação direta da Psicologia na elaboração e avaliação de políticas sociais.

No que se refere à segunda justificativa mais frequente, foi recorrente atribuir a importância da tese a contextos e situações problemáticos encontrados na sociedade (26 teses), como por exemplo, os altos índices de violência, o aumento da desigualdade social e mudanças no mundo do trabalho como precarização e desemprego. Soma-se a isso, os casos em que a justificativa da tese se dá em função de características e comportamentos de um determinado grupo populacional (terceira categoria mais frequente, presente em 13 teses), o que requer um conhecimento especializado como no caso de crianças em situação de risco, adolescentes em conflito com a lei, pais com filhos com deficiências, sujeitos apenados, membros de cooperativas e moradores de comunidades pobres. Urra (2011) chama a atenção para o fato de que, a despeito das ciências em geral (e da Psicologia, em particular) não serem as protagonistas das transformações na sociedade, sua articulação com as demandas sociais de forma mais ampla não se restringe a uma questão de relevância social, mas de ética e compromisso com o cuidado e promoção do bem-estar da população.

Por fim, há um grupo de $20 \%$ das teses analisadas que se justificam em função de necessidades da própria Psicologia, seja porque há demandas para a intervenção profissional (justificativa de 13 teses), seja porque há carência na produção científica (apontado por 10 teses). Por um lado, há de se valorizar estas tentativas de atender as demandas da área e responder às reiteradas críticas que são dirigidas ao fazer profissional no âmbito das políticas sociais. Por outro lado, é importante se atentar para que tal argumento (produção científica que tenha como fim a retroalimentação da própria área) não resvale em uma atitude meramente "corporativista", que reforça a ideia da produção de uma "Psicologia para psicólogos", ou seja, que reforça a eterna formação e consumo de serviços psicológicos por parte dos próprios profissionais da área (Dimenstein, 2000).

A partir deste quadro, percebe-se que a predominância da produção científica de Psicologia sobre políticas sociais aqui analisada intenta atender a demandas outras, que vão além das necessidades da própria área, caracterizando uma Psicologia que não se encerra em si mesma, mas se articula com questões mais amplas, postas ao conjunto da sociedade.

A segunda variável de análise no que se refere à finalidade da produção diz respeito a qual âmbito os autores das teses esperam trazer contribuições com seus estudos ${ }^{4}$, o que foi organizado em três conjuntos de categorias. No que diz respeito ao primeiro $(n=68)$, as teses têm em comum o pressuposto de que sua contribuição se volta às intervenções nos desdobramentos da "questão social", ou seja, espera-se contribuir para o desenvolvimento de políticas, seus instrumentos de operacionalização e outras práticas semelhantes. Este dado é indicativo não só do caráter prático deste tema de estudo, mas também do potencial de contribuição da Psicologia para as políticas sociais e da ocorrência de respostas da academia a demandas concretas da sociedade.

Na sequência, em torno de $20 \%$ das teses analisadas pretendem contribuir para o desenvolvimento da própria Psicologia. Tomar a Psicologia como ponto de partida, objetivo e fim em si mesma pode trazer tanto implicações positivas quanto indesejáveis como já mencionado: se por um lado, subsidia o desenvolvimento e fortalecimento da área pela ampliação e qualificação de seu corpo teórico-metodológico, por outro lado pode reforçar a separação das disciplinas científicas 
e práticas profissionais, perdendo de vista o contexto social como totalidade.

Em uma perspectiva diferente a estas categorias, se apresentam as teses que intentam contribuir para ampliar o conhecimento sobre o fenômeno ou conceito estudados $(n=11)$ e promover retorno à população usuária/beneficiária de políticas sociais $(n=9)$, sem qualquer referência à exclusividade da área. São estudos sobre diversas matérias, como por exemplo solidariedade, violência, ideologia, saúde mental no trabalho, relação entre sociedade e meio ambiente e adoção, na primeira categoria, e juventude, infância, grupo de catadores e portadores de transtorno mental, na segunda. Nesse sentido, reconhece-se que tais trabalhos estão menos preocupados com especificidades da área, em tentativas de delimitar aproximações e diferenciações com outros campos em relação ao que competiria à Psicologia. De outro modo, vê-se nestas teses a valorização dos problemas do contexto social e da população-alvo, com os quais a área deveria se comprometer, como ciência e profissão.

Entende-se que, articulando os dados sobre justificativas e contribuições, no que se refere às finalidades para as quais se dirige o conhecimento produzido nas teses acadêmicas analisadas, é possível organizá-las em três eixos centrais: aquelas que se voltam diretamente para o desenvolvimento da Psicologia, outra parcela que se direciona para as próprias políticas sociais e um terceiro conjunto diretamente articulado com o contexto social que suscita intervenções.

O debate que aparece na produção que aponta para a via da Psicologia se caracteriza, primordialmente, pelo reconhecimento de que as políticas sociais consistem em tema específico que merece a atenção da área, ou seja, relaciona-se à ideia de que é necessário construir conhecimento sobre este campo de intervenção profissional e pesquisa científica visando subsidiar a própria Psicologia. O segundo eixo em torno do qual se pode organizar o direcionamento da produção científica analisada se articula com a perspectiva das políticas sociais. Trata-se dos estudos que se dirigem às refrações da "questão social" e às práticas de intervenção, como políticas públicas específicas ou iniciativas emergentes da sociedade civil organizada. Este eixo se difere do anterior porque não pressupõe o debate da Psicologia, que pode ocorrer ou não, sendo que isso não é ponto central das teses. As produções assim classificadas representam tanto o potencial da Psicologia em promover avanços nas políticas sociais específicas (ou no entendimento dos contextos para os quais elas se aplicam), quanto revelam limitações por tomarem as políticas sociais como ponto de partida e admitirem como finalidade última a melhoria nas condições de vida da população, sem questionar o ciclo que demanda tais intervenções. O terceiro eixo de sistematização das finalidades das teses analisadas diz respeito à perspectiva crítica que introduz ou tenta aprofundar a ideia de transformação social na produção científica de Psicologia. São análises que consideram as formas e forças que regem a organização da sociedade e reconhecem os limites das políticas sociais como estratégias de erradicação dos problemas sociais próprios do modo de produção capitalista. Apesar de ser um debate mais marginal do que os dois eixos anteriores, no que se refere à frequência de ocorrência, percebe-se a presença desta discussão em alguns dos aspectos analisados. Importante que, nestes casos, foi apontada uma relação direta entre a produção científica e transformações no contexto social, sem se ater a mediações pela via da Psicologia ou das políticas e serviços estudados.

Este cenário aponta para a possibilidade de tratar-se de uma ciência que, uma vez preocupada com um projeto de sociedade, pode não apenas criticar leis, hipóteses e teorias, mas também indicar-lhes rumos fecundos e consistir em um novo tipo de universalidade científica (Henriques, 1978).

\section{Considerações Finais}

Ao se retomar o questionamento sobre a existência de preocupação por parte da pós-graduação stricto sensu de Psicologia em relação ao tema das políticas sociais, pode-se concluir que a resposta é positiva: as políticas sociais, de fato, figuram como campo de interesse para a pesquisa científica psicológica. As respostas relativas a "em que medida" e "como isso ocorre", entretanto, revelam um quadro a partir do qual não se pode mais fazer referência a uma produção científica de Psicologia sobre políticas sociais, mas a estudos com distintas características e vieses, produzidos em contextos também diferentes.

A questão que se coloca é se tais estudos podem ser considerados suficientes para habilitar a Psicologia a responder (ou participar da construção dessas respostas) aos graves problemas sociais postos à sociedade pela dinâmica do capital. E refletir sobre isso requer apontar os desafios presentes em torno de qualquer prática que se pretende crítica, mas condicionada à ordem do capital.

$O$ primeiro desses desafios diz respeito às condições em que ocorre essa produção científica. Sabe-se 
que a análise deste material, por mais que revele haver alguns exemplos de sistematização e institucionalização (por parte de alguns programas e de alguns orientadores), continua consistindo em experiências pontuais e isoladas frente à complexa atividade científica que cada vez mais se desenvolve. Tal constatação pode ser útil ao se pensar em políticas de indução sobre o tema na área, de forma a promover maior dinamização e consolidação de estudos sobre políticas sociais na Psicologia. Como afirma Bernal (1973), a atividade científica não é movida exclusivamente por uma força interna, tampouco segue uma direção independente. Portanto, para que se volte em favor do desenvolvimento do conjunto da sociedade, há de se pensar em colocar este tema deliberadamente como prioridade em sua agenda de pesquisa. Avaliar sistemática e frequentemente a própria produção científica parece ser uma estratégia viável para tal, a ser empreendida pelos próprios programas de pós-graduação de Psicologia como compromisso com a ciência psicológica e com a sociedade.

O segundo desafio para que a Psicologia possa impactar em um projeto de sociedade está relacionado aos limites próprios de uma perspectiva de análise condicionada pela divisão em disciplinas científicas. De acordo com Tonet (2013), os diversos campos disciplinares, ao se configurarem ao redor de dimensões isoladas da realidade social, delimitam seus objetos e seus métodos de estudo como se fossem partes inteiramente autônomas, dificultando uma correta compreensão da realidade como totalidade. Considerando isso, à Psicologia não mais caberia se referir às políticas sociais como algo naturalizado com a justificativa de não ser este seu escopo de estudo; de outro modo, mesmo se detendo nos aspectos que lhe são próprios, seria de sua responsabilidade não deixar de evidenciar como tais particularidades se relacionam e ajudam a explicar o processo histórico total. O aprofundamento onto-epistemológico e teórico-metodológico na produção científica sobre política social se faz urgente. Para tanto, se faz mister uma revisão sobre os moldes e os rumos que os cursos de graduação de Psicologia têm seguido, de forma a superar a formação aligeirada e tecnicista e direcionar os egressos para uma compreensão mais ampla das questões ontológicas, epistemológicas, metodológicas e temáticas.

O terceiro desafio posto à pós-graduação stricto sensu de Psicologia refere-se às definições em relação aos seus objetivos e aos destinatários do saber aí produzido. Isso requer colocar em pauta os pressupostos de neutralidade científica que ainda cercam a ciência contemporânea e tomar posição neste debate. É verdade que alguns debates promovidos pela política científica brasileira nos últimos anos têm ensejado que este aspecto seja abordado pela comunidade científica, mas encontra-se longe de estar no centro das prioridades dos pesquisadores, instituições e agências reguladoras e de fomento. A ideia de Inserção Social e popularização da ciência, presentes na avaliação dos programas de pós-graduação realizada pela CAPES, ainda carece de valorização e definição conceitual e operacional. É somente a partir de um aprofundado debate sobre isso que se pode pensar em um real compromisso por parte da comunidade científica em relação ao tema.

Para se pensar em algum potencial de contribuição efetiva desta ciência para a construção de uma nova realidade social, é urgente uma ação social, combinada e coordenada. A articulação em torno de um projeto ético-político para a Psicologia, então, parece ser um caminho possível, uma vez considerando que a história é uma construção coletiva, ainda que a partir de condições objetivas que estão fora de seu controle. Com isso, entende-se que apesar de haver obstáculos que dificultam, nada impede que a Psicologia redefina o papel social que sempre desempenhou, associado às funções de controle, segregação e legitimação da ordem (Furtado, 2012). O Sistema Conselhos de Psicologia assim como as diversas associações e sociedades científicas da área, a exemplo da Associação Nacional de Pesquisa e Pós-graduação de Psicologia (ANPEPP) e da Sociedade Brasileira de Psicologia (SBP), podem ser protagonistas neste processo.

Entende-se, assim, que colocar a ciência a serviço do conjunto da sociedade significa reconhecer a necessidade e a urgência de se construir uma sociedade orientada pelas necessidades humanas. $O$ fato de o cenário da ciência psicológica ser este hoje, não significa, em absoluto, que se trate de um retrato estático. Entende-se que a atividade científica não corresponde simplesmente a uma ação pura do pensamento, desconectada do sistema sócio-histórico e produtivo, tampouco é meramente instrumento do capital, sem nenhuma força que lhe é própria - privilegiar apenas um desses momentos é desconsiderar a complexidade que marca este cenário. De outro modo, há de se lembrar de que esta mesma ciência, ao passo em que está historicamente submetida às condições materiais do real, é também uma construção ativa desta realidade. 


\section{Referências}

Aragaki, S. S., Spink, M. J., \& Bernardes, J. S. (2012). La Psicología de la Salud en Brasil: transformaciones de las prácticas psicológicas en el contexto de las políticas públicas en el área de la salud. Pensamiento Psicológico, 10(2), 65-82. Recuperado de http://www.scielo.org.co/ scielo.php?script=sci_arttext\&pid=S1657-89612012000200007\&ln $\mathrm{g}=\mathrm{en \& t}$ lng=es

Bastos, A. V. B., \& Gondim, S. M.G. (2010). O trabalho do psicólogo no Brasil. Porto Alegre: Artmed.

Bernal, J. D. (1973). Historia social de la ciencia. Barcelona: Península.

Boschetti, I. (2009). Avaliação de políticas, programas e projetos sociais. In Conselho Federal de Serviço Social \& Associação Brasileira de Ensino e Pesquisa em Serviço Social (Orgs.), Serviço social: direitos sociais e competências profissionais (pp. 575-592). Brasília: CFESS.

Coimbra, M. A. (1987). Abordagens teóricas ao estudo das políticas sociais. In S. H. Abranches, W. G. Santos, \& M. A. Coimbra (Orgs.), Política social e combate a pobreza (pp. 65-103). Rio de Janeiro: Jorge Zahar.

Coordenação de Aperfeiçoamento de Pessoal de Nível Superior. (2013). Documento de área 2013. Recuperado de http://www.capes.gov.br/ component/content/article/44-avaliacao/4681-psicologia

Dantas, F. (2004). Responsabilidade social e pós-graduação no Brasil: idéias para (avali)ação. Revista Brasileira de Pós-graduação, 1(2), 160-172. doi: 10.21713/2358-2332.2004.v1.46

Dimenstein, M. D. (2000). A cultura profissional do psicólogo e o ideário individualista: implicações para a prática no campo da assistência pública à saúde. Estudos de Psicologia, 5(1), 95-121. doi: 10.1590/ S1413-294X2000000100006

Féres-Carneiro, T., Bastos, A. V. B., Feitosa, M. A. G., Seidl-de-Moura, M. L., \& Yamamoto, O. H. (2010). Lacunas, metas e condições para a expansão da pós-graduação em Psicologia no país. Psicologia: Reflexão e Crítica, 23(supl. 1), 11-24. doi: 10.1590/S010279722010000400003

Frey, K. (2000). Políticas públicas: um debate conceitual e reflexões referentes à prática da análise de políticas públicas no Brasil. Planejamento e Políticas Públicas, 21, 211-259. Recuperado de http://www.ipea.gov.br/ppp/index.php/PPP/article/view/89

Furtado, O. (2012). 50 anos de Psicologia no Brasil: a construção social de uma profissão. Psicologia: Ciência e Profissão, 32(número especial), 66-85. doi: 10.1590/S1414-98932012000500006
González-Rey, F. (2013). O que oculta o silêncio epistemológico da Psicologia? Pesquisas e Práticas Psicossociais, 8, 20-34. Recuperado de http://www.ufsj.edu.br/portal2-repositorio/File/revistalapip/ Volume8_n1/PPP_Art_2.pdf

Guzzo, R., Marçal, C., \& Rybka, L. (2014). Diferentes facetas, problemas e potencialidades para a psicologia crítica no Brasil: a vida cotidiana da classe trabalhadora. Teoría y crítica de la Psicología, 4, 131-145. Recuperado de http://www.teocripsi.com/ojs/index.php/TCP/article/view/154

Henriques, L. S. (1978). Notas sobre a relação entre ciência e ontologia. Temas de Ciências Humanas, 4, 27-40.

Lacerda Junior, F. (2013). Capitalismo dependente e a Psicologia no Brasil: das alternativas à Psicologia Crítica. Teoría y crítica de la Psicología, 3, 216-263. Recuperado de http://www.teocripsi.com/ ojs/index.php/TCP/article/view/110

Löwy, M. (2007). As aventuras de Karl Marx contra o Barão de Münchhausen: marxismo e positivismo na sociologia do conhecimento. São Paulo: Cortez.

Macedo, J. P., \& Dimenstein, M. (2012). O trabalho dos psicólogos nas políticas sociais no Brasil. Avances en Psicologia Latinoamericana, 30, 189-199. doi: 10.12804/revistas.urosario.edu.co/apl/a.1437

Mészáros, I. (2004). O poder da ideologia. São Paulo: Boitempo.

Mishra, R. (1981). Society and social policy: theories and practice of welfare. Londres: Macmillan.

Netto, J. P. (2001). Capitalismo monopolista e Serviço Social. São Paulo: Cortez.

Oliveira, I. F., \& Amorim, K. M. O. (2012). Psicologia e política social: o trato da pobreza como "sujeito psicológico". Psicologia Argumento, 30(70), 559-566. Recuperado de http://www2.pucpr.br/reol/pb/index. $\mathrm{php} / \mathrm{pa} ? \mathrm{dd} 1=6142 \& \mathrm{dd} 99=\mathrm{view} \& \mathrm{dd} 98=\mathrm{pb}$

Oliveira, I. F., Dantas, C. M. B., Solon, A. F. A. C., \& Amorim, K. M. O. (2011). A prática psicológica na proteção social do SUAS. Psicologia \& Sociedade, 23(número especial), 140-149. doi: 10.1590/S010271822011000400017

Tonet, I. (2013). Interdisciplinaridade, formação humana e emancipação humana. Serviço Social \& Sociedade, 116, 725-742. doi: 10.1590/ S0101-66282013000400008

Urra, M. (2011). Ética, relevancia social y Psicología organizada. Psiencia - Revista Latinoamericana de Ciência Psicológica, 3(1), 57-59. doi 10.5872/psiencia.v3i1.73

Yamamoto, O. H. (2012). 50 anos de profissão: responsabilidade social ou projeto ético-político? Psicologia: Ciência e Profissão, 32(número especial), 6-17. doi: 10.1590/S1414-98932012000500002 


\section{Políticas sociais, pós-graduação, Psicologia}

${ }^{1}$ Dentre os vários entendimentos acerca do alcance das políticas de Estado no que se refere à melhoria das condições de vida da população, assume-se o enquadramento a partir da teoria social marxiana e da tradição marxista: políticas sociais como estratégias do Estado para lidar com as manifestações da "questão social", entendida como expressão das desigualdades sociais produzidas e reproduzidas na dinâmica contraditória das relações sociais existentes no modo de produção capitalista. Na prática, empreendidas de forma fragmentada e parcializada, garantem sua reprodução sem atingir, de fato, seus determinantes (Netto, 2001).

${ }^{2}$ Para esta classificação, recorreu-se ao trabalho de Coimbra (1987). Baseado no trabalho de Mishra (1981), o autor traçou um panorama das teorias explicativas acerca das políticas sociais, o que foi alvo de críticas e correções (a exemplo de Boschetti, 2009 e Frey, 2000). Mesmo assim, continua sendo utilizado como base para discussões em função da compilação que faz, para cada abordagem teórica sobre políticas sociais, de suas influências, seus principais expoentes, a explicação atribuída ao papel das políticas sociais e o impacto causado por elas na sociedade. Considerando este cenário, tal tipologia foi utilizada apenas como ponto de partida para a discussão a respeito dos fundamentos teóricos dos trabalhos acerca das políticas sociais.

${ }^{3}$ Para tal análise, utilizou-se como referência o estudo de Lacerda Junior (2013), que analisa as abordagens teóricas que compõem a chamada Psicologia Crítica, tomada pelo autor como um conjunto de teorias e práticas que "buscam contribuir para algum projeto emancipatório e/ou elaborar novas formas de pensar o indivíduo, a subjetividade, o sujeito e outras categorias importantes para a Psicologia" (p. 217)

${ }^{4}$ Importante ressaltar que se trata de contribuições esperadas pelos autores das teses, sem ter havido qualquer julgamento em relação ao cumprimento desta expectativa, muito embora se reconheça a importância de se ter clareza da intenção para a consecução do objetivo.

Ana Ludmila Freire Costa, Doutora em Psicologia pela Universidade

Federal do Rio Grande do Norte (UFRN), é Pós-doutoranda na Universidade Federal do Rio Grande do Norte (UFRN). Endereço para correspondência: Av. Miguel Castro, 1519/702, Lagoa Nova, Natal-RN. Telefone: (84) 3025-8389. E-mail: analudmila@gmail.com

Oswaldo Hajime Yamamoto, Doutor em Educação pela Universidade de São Paulo (USP), é Professor Titular aposentado da Universidade Federal do Rio Grande do Norte (UFRN). E-mail: oswaldo.yamamoto@gmail.com

Recebido em 05.Out.15

Revisado em 30.Nov.16

Aceito em 31.Dez.16 